\title{
A educação física no currículo da formação de professores primários no Rio Grande do Sul (1877-1927)
}

VANESSA BELLANI LYRA Universidade de Caxias do Sul, Caxias do Sul, RS, Brasil

JANICE ZARPELLON MAZO

Universidade Federal do Rio Grande do Sul, Porto Alegre, RS, Brasil

TUANY DEFAVERI BEGOSSI

Universidade Federal do Rio Grande do Sul, Porto Alegre, RS, Brasil

\section{RESUMO}

O presente estudo buscou investigar as práticas e as representações culturais aferidas à área de conhecimento da educação física na formação de professores para atuar nas escolas primárias do Rio Grande do Sul. Para buscar compreender esse cenário a partir de uma perspectiva sócio-histórica, examinaram-se leis e relatórios expedidos no período, além de decretos, currículos oficiais de formação docente e currículos dos cursos de formação de professores. A análise das fontes identificou que vagarosamente a educação física adentrou os currículos dos cursos de formação de professores do estado, apoderando-se de tempos e espaços um pouco mais amplos. Ademais, essa condição foi influenciada na medida em que a educação física foi sendo considerada como um elemento de transformação nos debates educacionais modernos.

história da educação; história da educação física; formação de professores; escola. 


\title{
PHYSICAL EDUCATION IN THE CURRICULUM OF PRIMARY SCHOOL TEACHER TRAINING IN RIO GRANDE DO SUL (1877-1927)
}

\begin{abstract}
The present study sought to investigate the practices and cultural representations assessed in the physical education field, specifically, in the training of teachers to work in primary schools in Rio Grande do Sul. In order to understand this context from a socio-historical perspective, laws and reports issued during the period, as well as decrees, official teaching curriculum, and teacher training course curricula were examined. An analysis of the sources identified that physical education slowly entered the curriculum of training courses for state teachers, with more and more time spent on it. In addition, this was influenced by the fact that physical education was considered an element of transformation in modern educational debates.
\end{abstract}

KEYWORDS

history of education; history of physical education; teacher training; school.

\section{LA EDUCACIÓN FÍSICA EN EL CURRICULO DE LA FORMACIÓN DE PROFESORES PRIMARIOS EN RIO GRANDE DO SUL (1877-1927)}

\section{RESUMEN}

Este estudio tuvo como objetivo investigar las prácticas culturales y representaciones medidas al área de conocimiento de la educación física, en la formación de profesores para trabajar en las escuelas primarias en Rio Grande do Sul. Para tratar de comprender este escenario desde una perspectiva sociohistórica, se examinaron leyes e informes emitidos durante el período, así como los decretos, planes de estudios oficiales de la formación del profesorado y programas de estudio de los cursos de formación del profesorado. $\mathrm{El}$ análisis de las fuentes identificó que entró lentamente el programa de educación física de los cursos de formación de maestros del estado, apoderándose de tiempos y espacios un poco más amplios. Por otra parte, esta condición fue influida en la medida en que la educación física estaba siendo considerada como un elemento de transformación en los debates educativos modernos.

historia de la educación; historia de la educación física; formación de profesores; escuela. 


\section{CONSIDERAÇÕES INICIAIS}

Ao despedir-se, aos poucos, dos ditames imperiais e de todas as convicções que lhes eram caras, a República Federativa do Brasil emergia, a partir de 1889,impulsionada por um ideário político que reclamava por mudanças sociais de toda ordem. Imerso em um contexto conturbado, atravessado pelas inseguranças e pelo terror da guerra, o Novo Regime anunciava ideais de um país que se pretendia ao alcance de todos ao lutar em defesa da emancipação social dos cidadãos brasileiros. Era necessário, pois, reorganizar as estruturas sociais vigentes, adotando em suas bases um discurso unificador em prol do bem público: ao novo Brasil, "conservar, melhorando" (Castilhos, 1895, p. 12).

Nesse caminho, os chamados "negócios da administração do Novo Regime", subordinados à Secretaria do Interior, foram conduzidos por novos métodos, afeitos às tendências defendidas pelos ideários republicanos. Sem a menor cautela em registrar nos textos legais as oposições à administração imperial, os novos governantes reorganizavam a vida da sociedade sul-rio-grandense a partir de transformações no Serviço da Higiene Pública, no Serviço Policial, na Magistratura, na Brigada Militar e, indubitavelmente, na Instrução Pública.

Nesse contexto, em que a sociedade brasileira de uma forma ampla foi mobilizada pela atmosfera revolucionária republicana de modernização conservadora, os elementos históricos nos permitem perceber que a conjuntura estabelecida, em fins do século XIX e início do século XX, apontavam para um duplo movimento: o abandono da velha ordem e a consequente constituição de outra. Desse modo, não custa reiterar que a instrução pública, ou seja, a educação ocorrida nas escolas recebeu espaço significativo entre as preocupações norteadoras do Novo Regime.

No rol dos elementos fundamentais para a consolidação do novo projeto, a escola pública no Rio Grande do Sul despontava, assim, como uma das instituições sociais que urgiam por reformulações basilares em sua estrutura, meios e fins. Expressando uma influência positivista ${ }^{1}$, os documentos republicanos advogavam uma ideia de educação enquanto processo de adaptação do indivíduo ao novo meio social emergente, no qual os mais experientes - entre estes, os(as) professores(as) ${ }^{2}$ — começavam a ser reconhecidos como peças fundamentais no processo de socialização. Se o projeto era a construção de um novo país, edificação essa sustentada por outros pilares que não os que existiam até então, faziam-se necessárias a produção e a circulação de novas crenças, que conduzissem os rumos do país a novos pontos de chegada.

De maneira mais ampla, essa compreensão política afirmava, em seu bojo, que o nascimento de um novo Brasil estava na dependência do surgimento de um novo brasileiro, educado e instrumentalizado para a (re)construção do país. Assim, ao nascimento biológico de crianças e jovens se sobrepunha um novo, marcado pela gestação de novos valores sociais adequados ao momento em questão: a formação do ser social. Eis que, por conseguinte,

1 Para compreensão do pensamento positivista sobre a educação, sugere-se a leitura da obra "Educação e Sociologia", de Émile Durkheim. Com relação às conformações do positivismo educacional no estado do Rio Grande do Sul, ver Corsetti (2008).

2 Ao longo do texto passaremos a utilizar a forma "os professores" para nos referirmos tanto aos professores do sexo masculino quanto às professoras do sexo feminino. 
uma das primeiras medidas levadas a feito no país, a partir do advento da República, foi a de instrumentalizar, a passos mais largos, a formação de professores primários.

Justamente, é no campo da formação de professores para atuar nas escolas primárias do Rio Grande do Sul que recai o enfoque do presente estudo, mais especificamente sobre os espaços que a educação física passou a ocupar na vida social do novo país. Aos poucos, o que começou a ser observado - nos textos legais, nos currículos das escolas primárias e, sobretudo, nos currículos dos cursos de formação de professores - foi o fato de que as práticas de educação física foram adquirindo tempos e espaços ligeiramente mais amplos nos arranjos educacionais, ainda que esse processo não tenha se dado em avanço linear. Houve tensão entre presença e ausência, entre aumento e diminuição dos tempos e, consequentemente, o que esse cenário nos parece deflagrar. É plausível que a educação física passou a ser importante não somente na vida escolar, como também na vida social do novo Brasil.

Nesse contexto, o presente estudo buscou investigar as práticas e representações culturais aferidas à área de conhecimento da educação física na formação de professores para atuar nas escolas primárias do Rio Grande do Sul, no período de 1877 a 1927. O recorte temporal se justifica por ter sido 1877 o ano em que ocorreu a inclusão da disciplina denominada Gymnastica, Esgrima e Exercícios Militares no currículo de formação docente da Escola Normal; e 1927 por ser o ano de expedição de um novo Regimento Interno destinado aos estabelecimentos de ensino público do estado.Para o alcance do objetivo proposto, a partir de uma perspectiva sócio-histórica de análise, foram interpretados documentos escritos, sobretudo leis e relatórios expedidos no período, tidos como meios de orientação educacional; além de decretos, currículos oficiais de formação docente e de cursos específicos de formação de professores. Tais fontes foram concebidas enquanto materiais mensageiros de sentidos e finalidades particulares àquele contexto. Nesse viés investigativo, a análise dos referidos documentos foi realizada tendo por base as técnicas da análise documental (Pimentel, 2001; Corsetti, 2006).

De tal modo, interpretadas, as fontes históricas nos permitiram reunir as informações coletadas, as quais são apresentadas nos tópicos que seguem.

\section{A ESCOLA NORMAL E A FORMAÇÃO DE PROFESSORES PRIMÁRIOS}

À aurora do Novo Regime, a formação de professores primários, no Rio Grande do Sul, concentrava-se na Escola Normal situada na capital do estado, Porto Alegre. Idealizada ainda no ano de 1842, pelo então Imperador D. Pedro II, a Escola Normal iniciou suas atividades efetivamente no ano de 1869, após um longo período de variações orçamentárias, que ora faziam avançar, ora retroceder suas obras. De tal modo, a referida instituição foi estabelecida em 05 de abril de $1869^{3}$, reformada em 07 de abril de $1877^{4}$, e reorganizada em 04 de fevereiro de $1881^{5}$.

3 Embora instituído no ano de 1869, o primeiro regulamento da Escola Normal foi aprovado no ano de 1872, pelo Acto Provincial de 19 de fevereiro de 1872 (Rio Grande do Sul, 1872).

4 Lei Provincial n. 32, de 7 de março de 1877 (Rio Grande do Sul, 1877).

5 Lei Provincial n. 1.340, de 27 de maio de 1881 (Rio Grande do Sul, 1881). 
Ainda, no período do governo imperial, conduzindo nosso olhar para as práticas de educação física que fizeram parte das grades curriculares da Escola Normal, podemos perceber uma primeira tentativa de inserção dos saberes da área, por meio da disciplina de número nove que, no ano de 1877, correspondia às práticas de Gymnastica, Esgrima e Exercícios Militares, ausentes no currículo de 1872. Ao analisar o regimento de 1877 , no qual estava explicitada a respectiva grade curricular, o inciso segundo do artigo de número 3 nos chama a atenção de um modo particular. Faz menção à distribuição das disciplinas ao longo dos três anos do Curso Normal. O inciso determinava que o ensino das disciplinas de Grammatica philosophica ${ }^{6}$, Pedagogia, Arithmetica e geometria plana, Geographia, cosmographia, Historia, Língua franceza, Desenho linear, figurado, de paisagem, topographico e de architectura, além da Calligraphia, estaria presente durante todo o tempo de formação, ou seja, durante os três anos. De outro modo, as disciplinas denominadas "Noçoes de phisica e chimica" e "Musica vocal e canto" foram destinadas aos dois últimos anos do curso.

O ensino da disciplina designada sob o número nove - Gymnastica, Esgrima e Exercícios Militares - estava restrito ao primeiro ano de formação, tendo sua abrangência permitida apenas aos professores do sexo masculino. Desse modo, colocando em diálogo as duas primeiras grades curriculares em questão, o seguinte quadro se delineava no ensino de educação física, aos futuros professores primários do Rio Grande do Sul, no final da década de 1870: apenas os professores homens, que houvessem cursado com êxito o primeiro ano de estudos da Escola Normal, estariam aptos e autorizados a ministrar aulas de educação física nas escolas.

Ainda que não consigamos precisar em números o ingresso de alunos do sexo masculino na Escola Normal de Porto Alegre, o que se pode afirmar é o fato de que, muito embora a política declarada nos instrumentos legais fosse a de reservar o espaço para homens, o magistério público era mais procurado por mulheres que por homens. Essa assertiva pode ser constatada no relatório apresentado ao presidente do estado do Rio Grande do Sul, Getúlio Vargas, pelo Secretário de Estado dos Negócios do Interior e Exterior, Oswaldo Aranha, no ano de 1929. O referido documento nos traz uma ideia da superioridade de matrículas de alunas em relação às de alunos na Escola Normal de Porto Alegre, desde sua reorganização, a saber: no ano de 1881, registrou-se a matrícula de 29 homens e 70 mulheres; em 1882, 43 homens e 74 mulheres; em 1883, 38 homens e 69 mulheres; em 1884, 39 homens e 80 mulheres; em 1885, 44 homens e 75 mulheres; em 1886, 51 homens e 84 mulheres; em 1887, 51 homens e 106 mulheres; em 1888, 56 homens e 115 mulheres (Aranha, 1929).

A superioridade de mulheres no magistério público estadual do período também foi evidenciada no estudo de Werle (2005). Essa autora revela que, mesmo objetivando formar professores homens para atuar no ensino das primeiras letras, muitas das matrículas da Escola Normal de Porto Alegre, em fins do século XIX, foram ocupadas por moças órfãs, advindas do Colégio Santa Tereza. Segundo Werle

6 Ressaltamos que, para fins deste estudo, optamos por manter a grafia das palavras conforme nos apresentaram as fontes consultadas. 
(2005, p. 613), no Rio Grande do Sul, constata-se uma “[...] situação de feminização imediata da formação para o magistério, vinculada à promoção de moças desvalidas".

Nesse momento que tangenciava a década de 1870, a educação física pouco se fez presente na preparação dos professores da Escola Normal, uma vez que a demanda de alunos se mostrava inferior à de alunas. Ao mesmo tempo, a situação se agravava ao pensarmos que a inserção da disciplina na grade curricular do curso de formação docente não implicou, nesse momento, uma efetiva remodelação dos espaços físicos das escolas primárias para atender às necessidades advindas das atividades práticas. Nesse passo, podemos assim pensar que a entrada da educação física na escola primária do Rio Grande do Sul ficava igualmente comprometida em suas potencialidades de legitimação e alcance enquanto saber curricular reconhecido.

Em um quadro de ausências iniciais, ainda que presente a sensação fugidia de pontuarmos a origem dos fatos históricos, lançamo-nos aqui ao desafio (transitório) de afirmarmos que as primeiras tentativas de se estabelecer uma sistematização para a formação de professores de educação física no Rio Grande do Sul se deram, justamente, a partir da criação da primeira Escola Normal de Instrução Primária, na capital do estado. De acordo com Piccoli (1994, p. 20), o primeiro professor a assumir a cadeira de Ginástica na referida instituição foi Edmundo Muniz de Bittencourt ${ }^{7}$.

A lei provincial n. 1.340, de 27 de maio de 1881, aprovou o terceiro regulamento da Escola Normal e, em seu bojo, havia o anúncio de uma nova grade de saberes curriculares. Essa reorganização anunciada no título do documento ${ }^{8}$ refletia na mudança de algumas estruturas definidas pelo regulamento anterior, como, por exemplo, a ampliação do curso de estudos oferecido para quatro anos: o primeiro ano foi destinado ao Curso Preparatório ${ }^{9}$ e, os três últimos, ao Ensino Normal.

No rol das disciplinas curriculares previstas, assim como ocorrera no regulamento de 1872, novamente há a ausência de quaisquer referências ao ensino ligado às práticas de educação física. Entre avanços e retrocessos no campo da formação de professores no estado do Rio Grande do Sul, a grade curricular apresentada anteriormente aponta que a educação física novamente ficara à margem da preparação dos futuros professores. Esse fato é capaz de aprofundar ainda mais os questionamentos não somente sobre sua propagação enquanto saber escolar, mas, antes disso, sobre a sua simples presença nos ambientes escolares.

Com a principal finalidade de reorganização da instrução primária do Rio Grande do Sul, o então presidente do estado, Julio Prates de Castilhos, instituiu, no ano de 1897, o decreto estadual n. 89 (Rio Grande do Sul, 1897). Justificando a elaboração do documento, Julio de Castilhos inicia a redação do texto de forma pro-

7 Bittencourt era militar e exerceu também função docente na Escola Militar no Rio de Janeiro até o ano de 1882, onde recebia a titulação de Mestre de Ginástica.

8 Documento redigido, em 1881, pelo presidente da Província do Rio Grande do Sul, Francisco de Carvalho Soares Brandão, sob a denominação de Regulamento para a Reorganisação da Escola Normal (Rio Grande do Sul, 1881, p. 325).

9 O Curso Preparatório foi criado em 1881 para preparar e habilitar os alunos das escolas primárias para o ingresso no Curso Normal, bem como para servir de campo para a prática de ensino dos alunos formandos do terceiro ano do Curso Normal (Rio Grande do Sul, 1881). 
vocativa, considerando a necessidade de reorganizar o serviço da instrução primária de acordo com o que considerava ser as novas exigências do ensino. Nesse sentido, abrir-se ao "novo" significava, entre outras disposições, fechar-se ao "velho" e já considerado ultrapassado ensino do período imperial.

Desde o anúncio, feito dois anos antes de sua execução, o projeto carregava consigo a promessa de equiparação da instrução pública sul-rio-grandense aos demais ramos da administração estadual, no que tange à qualidade de organização. Ao que parece, por motivos de má distribuição orçamentária, havia um grande contraste entre as ampliações e os progressos que ocorriam nos demais departamentos da administração pública e aqueles delineados pelo campo da educação. Já se fazia hora de dar atenção a esse ramo do serviço estadual, não tardando em dar início, como defendia Julio de Castilhos (1896, p. 15), à sua "imprescindível reorganisação".

Nesse primeiro documento educacional republicano de extensão estadual, a reforma por ele proposta mobilizava, pois, uma natureza grandiosa a ser reestruturada. Caracterizava-se, entre outras promessas, pela garantia da estabilidade; pela unidade de direção, tão ausente nas escolas da Corte; pela laicidade, liberdade e gratuidade do ensino primário. De um modo particular, a Reforma de 1897 reclamava como sua a responsabilidade "pela aptidão profissional e moral do professorado e de todos aquelles que exercem funç̧ôes de direç̧ão e inspeç̧ão" (Castilhos, 1896, p. 16), ou seja, entre as primeiras medidas anunciadas estava uma melhor preparação para os professores. Em linhas gerais, previa-se e defendia-se um ensino primário livre, leigo e gratuito a ser ministrado pelo próprio estado, no interior de duas novas organizações escolares: os colégios distritais e as escolas elementares.

\section{A EXPANSÃO DA FORMAÇÃO DO PROFESSORADO PRIMÁRIO}

A nova organização da educação primária do estado destinava ao Curso Complementar a função principal de formação do professorado primário, antes concentrada na Escola Normal da capital, e ao Curso Elementar a responsabilidade pela educação primária das crianças. Por sua vez, os Cursos Complementares deveriam ser ministrados dentro de uma nova configuração escolar que emergia: os colégios distritais.

Em substituição à Escola Normal da capital, instituição única e distante das mais longínquas regióes do estado, os colégios distritais representaram uma tentativa de expansão da formação de professores no Rio Grande do Sul, ao criar unidades espalhadas por toda a extensão de seu território. Pela política de criação de mais colégios distritais, a formação de professores ganharia, num primeiro momento, em quantidade, por meio dos cursos de estudo complementares, que habilitavam os alunos ${ }^{10}$ ao magistério primário. Logo após a criação do colégio distrital da capital, em 1901, inaugurava-se um colégio na cidade de Santa Maria e outro em Cruz Alta (Rio Grande do Sul, 1901c). Na sequência da política de multiplicação, foram criados, em 1902, colégios similares em Santa Cruz, Taquary e São João do Montenegro (Rio Grande do Sul, 1902). Desse modo, o processo

10 A escrita refere-se aos alunos de modo geral, incluindo aqueles do sexo masculino e feminino. 
continuava avançando por todo o estado, até que, a partir de 1905, alguns colégios distritais começaram a ser suprimidos por falta de procura, sendo quase nula, em muitos casos, a frequência ao curso.

As fontes apontam o ano de 1901 como aquele em que a nova política de formação do professorado primário é realmente efetivada a partir da criação, na capital, do primeiro colégio distrital (Rio Grande do Sul, 1901a). Em substituição à Escola Normal, criada em 1869, o colégio era organizado em duas seções que deveriam funcionar separadamente: uma para os alunos e outra para as alunas. Cabe ressaltar que, em sua organização temporal, o Curso Complementar estaria separado em três classes (três anos), em que haveria um único professor para cada classe, responsável pelo ensino de todas as disciplinas (Rio Grande do Sul, 1901).

Ao observarmos a cadeira de Gymnastica, no rol das disciplinas curriculares, constatamos que, embora presente nas três classes, novamente é elencada em último lugar na ordem dos saberes. Ao mesmo tempo, se comparado o tempo destinado aos seus conteúdos com aquele destinado à disciplina de Portuguez, por exemplo, vemos que as diferenças são aí multiplicadas por seis. Nesse quadro, o professorado primário que estava a se formar pelo Curso Complementar assistia a uma hora de aula de Gymnastica, ao longo de suas 28 horas de aulas que compunham a semana escolar (Rio Grande do Sul, 1901b).

De tal modo, parece que à educação física caberia um movimento de entrada sutil e lento no ambiente educacional formal, adequado também ao ritmo do reconhecimento que a educação integral do aluno conquistava no âmbito mais geral do pensamento educacional sul-rio-grandense. Sopravam-se, assim, no estado do Rio Grande do Sul, os ares de uma modernização da escola trazidos, entre outras, pela ideia de um currículo de formação que começava, paulatinamente, a abrir espaço à compreensão do movimento corporal sistematizado como saber educacional legítimo.

De outro modo, é possível pontuarmos que a presença da educação física enquanto disciplina curricular nos cursos de formação docente não obedeceu a uma trajetória linear, nem mesmo no que diz respeito à sua denominação. Um exemplo marcante desse feito de mudanças e transformações constantes é a situação trazida pelo currículo do Curso Complementar de 1906. Se um olhar apressado sobre sua organização admite afirmar novamente a ausência da educação física no arranjo curricular, um pouco mais de cautela na análise das ementas das respectivas disciplinas nos traz à tona a informação de que as práticas ligadas à educação física estariam inseridas na disciplina denominada de Pedagogia, cuja descrição de conteúdos era a seguinte: "Pedagogia — sua historia, educação physica, intellectual e moral, methodologia, practica do ensino" (Rio Grande do Sul, 1906). Ao que parece, havia, a partir da atenção dada ao corpo, um alargamento da compreensão da disciplina denominada Pedagogia, antes concentrada apenas no aperfeiçoamento das dimensões intelectuais e morais.

Destarte, começaram a surgir nos currículos de formação de professores no Rio Grande do Sul dois termos que passavam a relacionar-se com a educação física: a Gymnastica, disciplina específica, compreendida como uma forma particular de sistematização dos movimentos corporais; e a educação physica, saber que emergia 
da disciplina de Pedagogia e localizava-se para além desta, como uma prática escolar que deveria apresentar um sentido amplo ao irradiar-se a todas as faces da cultura escolar $^{11}$. Embora distintas, Paiva (2003) nos lembra do sentido precípuo que as une: suas finalidades educacionais e pedagógicas.

Se nesse momento o interesse recai sobre a educação physica, cabe aqui lembrarmos a contribuição do trabalho de Vago (2002), cujo espaço escolhido foi a escola mineira à aurora do século XX. Estudando de forma pormenorizada ambos os significados supracitados, o autor nos faz conjecturar sobre a realidade sul-rio-grandense, ao pontuar as diferenças e semelhanças do processo de construção de sentidos que sustentavam a educação physica enquanto verdade a ser refletida e vivenciada naquele momento e ambiente escolar.

Abordada por Vago (2002) como um artefato da cultura escolar, a educação physica ligou-se diretamente a uma ideia de criação de hábitos saudáveis e moralmente educados e foi atravessada pelas noções médicas de higiene, prevenção de doenças e manutenção da saúde. De outro lado, a educação physica também disse respeito a uma noção de conformação dos corpos infantis ao espaço valoroso do ambiente escolar, ou seja, aquele que representava, em menor escala, a nova sociedade que se almejava construir.

Em linhas gerais, como afirma Vago (2002, p. 22), o papel educacional e pedagógico da educação physica encontraria sua razão de ser ao realizar “[...] a façanha de, a um só tempo, destruir hábitos trazidos de casa, da rua e inscrever nos toscos corpos infantis maneiras consideradas civilizadas". Nessa compreensão, o autor sublinha que tal saber, de caráter geral e abrangente, poderia facilmente ser percebido nos diferentes programas de ensino, na organização dos tempos e espaços escolares, na higiene e inspeção médica nas escolas e em suas rotinas.

Para além, Pykosz e Taborda de Oliveira (2009) referem que o mobiliário escolar tem significativo destaque nos estudos sobre higiene devido à sua importância quanto a aquisições de hábitos que ele pode conformar, causar ou evitar, já que tal elemento incide diretamente nos corpos dos escolares. Os autores apontam que o mobiliário passou a representar uma preocupação que reuniu médicos e arquitetos escolares ao seu entorno, sobretudo pelas questões relacionadas à postura e às formas adequadas de tratos corporais.

É interessante destacarmos que esses aspectos são apontados também por Viñao (1995) justamente como os mais relevantes na conformação das culturas escolares e, por sua vez, encontram eco nos termos de Vidal e Faria Filho (2005), para quem são igualmente considerados como os princípios ordenadores da escola. Nesse sentido, a análise do quadro elaborado por Lyra (2013) sobre a carga horária semanal das disciplinas do Curso Complementar, conforme decreto n. 874, de 28 de fevereiro de 1906, revela que, nas duas primeiras séries do aludido curso, as futuras complementaristas nada recebiam sobre os conhecimentos acima referidos, ficando esse ensino apenas para a terceira e última série.

11 Sobre cultura escolar, ver "A cultura escolar como objeto histórico", escrita por Dominique Julia (2001). 
A situação de escassez de tempo/espaço na referida formação ainda se agrava quando pensamos na ideia de que apenas duas horas semanais eram então destinadas à disciplina de Pedagogia. Nesse entendimento, é necessário lembrarmos que, no interior dessa disciplina, a educação physica não era conteúdo hegemônico, mas sim dividia espaços com os outros saberes, advindos das dimensões intelectual e moral, conforme citado. Em compasso com os contornos (ou a falta deles) em que se encontrava a referida disciplina, a formação de professores para o trabalho com a educação physica no estado sul-rio-grandense anunciava algumas características peculiares.

\section{FORMAÇÃO DE PROFESSORES PARA A EDUCAÇÃO PHYSICA}

O quadro inicial de professores que se delineava no estado do Rio Grande do Sul reproduzia a representação mais geral do país, onde a especialização do professor na área não era o foco principal, já que a própria noção de educação physica se encontrava dispersa pelo currículo de formação docente. Se é certo que procuramos encontrar na História as estruturas já firmadas e consolidadas da educação física que hoje conhecemos, ou seja, de um campo do saber, é necessário seguirmos firmes na trama histórica, na mesma proporção em que é preciso seguirmos pacientemente.

O que queremos dizer com essa reflexão é que nesse momento histórico em que vimos uma área adentrar vagarosamente os currículos dos cursos de formação docente no Rio Grande do Sul, o enredo principal não se mostrou afeito à ação de diferenciar seus saberes dos demais, especializando profundamente a figura de um professor para tal trabalho. Antes, a ideia de concentrar os saberes no interior de disciplinas pontuais (Gymnastica) ou de espalhá-los por todas as dimensões da cultura escolar (educação physica), revela justamente essa atmosfera processual que marcou a trajetória histórica da disciplina que hoje conhecemos como educação física.

$\mathrm{Na}$ esteira dessas evidências, é necessário compreendermos que os cursos de formação docente disponíveis no momento agiam mais no sentido de preparar (mesmo que minimamente) o professor para o trabalho com a educação física - em seu duplo sentido - do que, propriamente, formar um professor específico para a educação física. Esse olhar, que à primeira vista se mostra tão evidente, nos convida a repensar os pensamentos circulantes sobre a carência de professores especializados e, principalmente, sobre seu enfoque como um problema a ser superado. Ao menos nesses momentos iniciais de formação do campo, a carência a que nos referimos não foi compreendida como um problema, mas sim como parte do processo. Afinal, para que a falta de professores de educação física tenha se tornado um problema histórico a ser solucionado, foi necessário, primeiramente, que a própria educação física tivesse se tornado um elemento essencial para a educação, com seus contornos e finalidades bem definidos. E, nesse momento, ao que sugerem as fontes, essa posição ainda não havia sido alcançada no arranjo curricular.

Foi também no interior da disciplina de Pedagogia - anunciada na grade curricular da Escola Complementar do ano de 1909 - que pudemos localizar pontualmente os limites que diferenciavam a educação physica da Gymnastica. Nessa ocasião, os dois saberes, conjuntamente, passaram a fazer parte do rol de elementos a serem 
trabalhados, o que deflagrou uma definição de suas fronteiras educacionais e, ao mesmo tempo, uma diferenciação de suas finalidades no espaço escolar.

Nesse cenário, o quadro sobre o currículo de formação dos professores da Escola Complementar elaborado por Lyra (2013), tendo por base o decreto n. 1.479, de 26 de maio de 1909, socializava os professores sul-rio-grandenses a partir de um modelo particular de ginástica, a saber: a Gymnastica Sueca. Esse modelo (ou método) particular teve grande aceitação no Brasil, na virada do século XIX para o $\mathrm{XX}$, sendo defendido fervorosamente por intelectuais da época, como Rui Barbosa

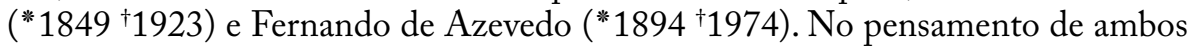
é possível identificarmos um esforço de especificação da nova área, com vistas a que ela fosse aceita e compreendida nos currículos de formação: em Rui Barbosa, encontramos recorrentemente a menção feita à ginástica, ao passo que em Fernando de Azevedo tal especificação já é tratada como educação física.

Entender a participação de Rui Barbosa na construção de um pensamento inaugural em defesa da ginástica no ambiente escolar requer que, simultaneamente, tenhamos clareza do contexto em que este estava inserido e que impulsionou a emergência, ainda que não explícita ${ }^{12}$, de um novo significado às práticas corporais. Advogado fervoroso das possibilidades emancipatórias da educação pautadas, sobretudo, na liberdade de ensino, Barbosa (1946, p. 61) dedicava seus esforços no sentido da superação da ignorância popular, elegendo a educação primária como foco principal e indispensável a esse processo. Imerso em suas concepções políticas liberais, o intelectual propôs mudanças significativas na inércia que pairava sobre os estabelecimentos, os conteúdos e os métodos de ensino de sua época, responsabilizados, segundo ele, por serem os causadores da "morte da inteligência".

Entendia que a organização do ensino no modo como se apresentava não atingia a infância escolarizada pelo fato de não estar ao alcance de suas possibilidades naturais, pertencentes à própria escala evolutiva do ser humano. Nesse sentido, a educação se encontrava na contramão do processo modernizador, funcionando como um verdadeiro obstáculo em lugar de um trampolim que elevasse a população brasileira aos patamares do progresso. Era preciso adequar o ritmo escolar ao ritmo biológico das crianças e, assim, vislumbrar a possibilidade de "desenvolver harmonicamente, pela sua gradação natural, todas as faculdades e energias humanas condenadas pelos métodos atuais a eterno letargo" (Barbosa, 1946, p. 60).

Ao prescindir, explicitamente, corpo e espírito, Barbosa (1946, p. 49) afirma que a escola de seu tempo, desconhecendo as "leis fatais do desenvolvimento fisiológico da criança”, em vez de incentivar a evolução natural e crescente da vida orgânica, não atua sobre ela senão como uma das influências mais prejudiciais, não levando a outro fim que não seja a depauperação da espécie. $\mathrm{O}$ autor alerta que a natureza, no entanto, não abre mão dos seus direitos e, assim, dá voz ao que parece ser um dos eixos principais de sua proposta: "a higiene do corpo e a higiene da alma são inseparáveis" (Barbosa, 1946, p. 49).

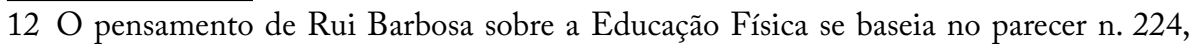
expedido no ano de 1882, referente à Reforma Leôncio de Carvalho oficializada pelo decreto n. 7.247, de 19 de abril de 1879. Neste estudo, valemo-nos da versão publicada, em 1946, pelo Ministério da Educação e Saúde. 
Responsável pela renovação das energias intelectual e espiritual desgastadas pelo esgotamento provocado pela dedicação assoberbada às demais disciplinas, a inclusão da prática regular da ginástica é proposta por Rui Barbosa, que inspirou-se, para tanto, nos resultados obtidos nas nações de grande potência mundial. Esta seria matéria de estudo nos currículos das escolas primárias, secundárias e, inclusive, na preparação dos professores primários. Ao passo que essa inclusão se daria em momentos distintos do recreio e após o período diário das aulas.

É nesse ideário de preocupação com a saúde dos corpos dos alunos, em busca da educação do novo indivíduo que formaria o novo Brasil e, diante do seu caráter científico ${ }^{13}$ sustentado por pesquisas na área da fisiologia, biologia e anatomia, que a ginástica recebe importância áurea no ideário educacional de Rui Barbosa e, sobretudo, em suas proposições de mudanças. No que tange à formação de professores para ministrar a disciplina e diante de tamanha importância que seus argumentos usavam para justificá-la, Barbosa (1946) anuncia o ineditismo de uma intenção de consolidar a formação especializada, por meio da criação de uma Escola Normal de Ginástica. No entanto, seus anseios foram limitados no arranjo curricular dos cursos de formação docente. É por meio de sua proposta que surge também uma das primeiras tentativas de reconhecimento do valor individual dos professores especializados na área, reivindicando para estes a equiparação em categoria e autoridade àqueles que ministravam as outras disciplinas escolares.

O então circulante Método Alemão de Ginástica, que, segundo Tesche (2008), apresentava uma conotação militarista e buscava a fortificação da raça, tão defendida pelos higienistas, era recusado por Rui Barbosa. Os objetivos do referido método, que também agrupava um conjunto de atividades culturais denominadas Turnen $^{14}$, discordavam daqueles que o intelectual compreendia fazer parte da ginástica inscrita no compasso dos objetivos educacionais mais amplos. Como a escola não deveria ter a finalidade, em seu entender, de sustentar um sistema que convertesse os alunos em ginastas profissionais ou militares especializados, Rui Barbosa propõe a substituição do Método Alemão pelo Método Sueco, que julgava mais adequado à realidade escolar pretendida, atual e futura.

No entanto, se primando por um simétrico desenvolvimento muscular com vistas às exigências da maternidade futura sem, contudo, "acarretar prejuízo da doçura e das maneiras, da graça e elegância do talhe, da bela harmonia das formas femininas" (Barbosa, 1946, p. 91) às mulheres, o parecer propunha uma combinação do ritmo e do canto com a ginástica, encerrando-se mais especificamente na calistenia ${ }^{15}$.

13 De acordo com Soares (1994, p. 182), esse caráter científico foi responsável por conferir à ginástica um status diferenciado que possibilitou a expansão do pensamento higienista no período republicano.

14 Para Tesche (2008, p. 250), “o Turnen não era somente a prática da ginástica, mas o teatro, o canto coral, a existência de bibliotecas, o bolão dentre outros que eram parte importante na afirmação da identidade do alemão e de seus descendentes”.

15 Marinho $(1943 ;$ 1952) aponta que a primeira referência que encontramos a favor da adoção da calistenia no Brasil situa-se nos pareceres de Rui Barbosa. Associada à música e ao ritmo, a calistenia tem origem na ginástica sueca e é o marco do desenvolvimento da ginástica moderna. 
Aos homens, com o intuito de cultivar as forças corpóreas e educar um caráter viril e, ao mesmo tempo, a exemplo das civilizações modernas, nutrir as crianças da arte da defesa de sua pátria, o documento propunha acrescentar à ginástica masculina os exercícios militares. Nesse quadro de solidariedade e incentivo à presença das práticas militares, Paiva (2004, p. 62) afirma ser o parecer de Rui Barbosa o instrumento que introduz incisivamente o sentido militar na educação física escolar brasileira.

O Método Sueco, em razão de sua dimensão pedagógica, também conquistou a simpatia de Fernando de Azevedo, que, em 1920, dedicava-se à publicação de suas duas primeiras obras, ambas destinadas à educação física ${ }^{16}$. Se Rui Barbosa concentrou seus esforços na preocupação com o desenvolvimento harmônico do corpo escolarizado, fazendo com que suas verdades se justificassem pelos males causados por um quadro de ausências que a sustentavam no cenário educacional, Fernando de Azevedo, vendo na educação física uma inspiração imensa e apaixonada para seus estudos, preocupou-se em justificá-la pelas luzes de suas funções (trans) formadoras diante da juventude.

Não se pode desconhecer quanto lucraria a mocidade moderna com esta compreensão mais ampla da escola [...] A educação física não serve apenas, como antes erradamente se cogitava, para favorecer o desenvolvimento harmônico do corpo, desempenha funções de não menor relêvo na formação da vontade e do caráter e no exercício das fôrças volitivas. Ela é parte integrante de todo um sistema de educação [...] tende antes de tudo a atuar sôbre o corpo humano, a enrijá-lo e a robustecê-lo, para atingir o plano psíquico e moral [...] (Azevedo, 1960, p. 23-24)

Mais do que entender que o contexto no qual Fernando de Azevedo implantou suas ideias relativas à educação, de um modo amplo, e à educação física, de um modo particular, seguia na esteira das aspirações de nacionalização e modernização da população brasileira anunciadas na proposta de Rui Barbosa, é necessário fazermos emergir um episódio da carreira de Fernando de Azevedo. Talvez esse registro concorra para nos aproximar de seu pensamento, que deixou marcas indeléveis em suas perspectivas educacionais, a ponto de tornar sua luta pela reforma educacional um modo de viver e a boa formação dos educadores brasileiros, um projeto majestoso.

De acordo com Lima (2002, p. 3), a primeira oportunidade de Fernando de Azevedo pôr em prática suas convicções aconteceu no ano de 1915, quando da verificação do funcionamento do ginásio do estado, em Belo Horizonte, observando o tipo de ensino ministrado, o regime de disciplina e a relação entre professores e alunos. No mesmo ano, responsabilizou-se pela reformulação do ensino de Educação Física nas escolas mineiras, enviando um projeto de lei ao governo de Minas Gerais com a proposta de tornar obrigatórias as aulas de educação física em todas as escolas, fossem essas particulares ou públicas. Neves (2002, p. 4) aponta que

16 A saber: "Da educação física: o que ela é, o que tem sido e o que deveria ser, seguida de Antinöus: estudo de cultura atlética”. 
tal projeto teve a aprovação da Câmara Estadual dos Deputados e, como autor do mesmo, Fernando de Azevedo se viu na obrigação de concorrer à então criada cadeira de educação física no ginásio do estado.

Diante da sociedade e da época em que vivia, era provável que o professor de educação física devesse ser dotado de plenas e explícitas aptidões físicas. Um jovem pequeno e franzino - próprio da juventude elitizada daquele momento, socializada em meio familiar e destinada aos livros e/ou à vida religiosa - não poderia atuar nesse departamento, mesmo que sua habilidade intelectual e didática, bem como sua disponibilidade à instrução, ultrapassasse em muito àquela apresentada pelo outro candidato, um pugilista, segundo o próprio Azevedo (1971). Malogrado a seu ver, por artimanhas políticas, o jovem educador perdeu a disputa com o outro candidato, que assumiu em seu lugar, a cadeira de educação física do ginásio mineiro.

Nesse concurso, Fernando de Azevedo apresentou o trabalho "A poesia do corpo", no qual, segundo Camargo (2006, p. 21), tendo como estratégia a educação física, o educador trabalhou com o conceito de nacionalidade e defendeu a tese de "regeneração social do país". Camargo (2006) aponta ainda que Fernando de Azevedo era guiado pela conviç̧ão da defesa da regeneração social em nível nacional, vendo na escola um espaço relevante para a obra de regeneração da sociedade, sendo que no campo educacional a educação física desempenhava um papel de suma importância.

A derrota fez com que Fernando de Azevedo retornasse ao Rio de Janeiro e lá acentuasse sua luta contra a pouca importância dada à prática do bom ensino. Segundo ele, os educadores de sua época privilegiavam a posse do conhecimento sem se preocupar, no entanto, com a forma de transmiti-lo. Nesse sentido, Neves (2002, p. 7) sustenta que, como reformador, Fernando de Azevedo defendeu a importância das práticas pedagógicas, ou seja, de que os professores saibam não só o que ensinar, mas como ensinar, de modo que, em seu pensamento, não deveria haver lugar para professores não engajados no ideário da então emergente Educação Nova.

Para uma Educação Nova, Fernando de Azevedo advogava uma Nova Educação Física que, a exemplo de Rui Barbosa, condenava ao fatalismo errôneo as finalidades extremas de exercitação do corpo, sustentadas a partir de prejuízos aos atributos intelectuais e morais. Sendo ponto passivo no pensamento de ambos, o exagero da exercitação dos músculos, que encontravam em si sua razão de ser, nada contribuía com alguma utilidade ao momento de transição em que se encontrava a sociedade brasileira, tampouco com as exigências de construção de um novo indivíduo social. Afinal, no entender de Fernando de Azevedo, no novo projeto de sociedade, baseado nas trocas, nas relações de competição mercadológica, devia-se buscar uma educação pelo esforço, pela fadiga enquanto meio educativo, e não desvirtualizadora da moral ou da valorização de sentimentos egoístas, prejudiciais ao engrandecimento social.

A ginástica sueca, sistematizada no início do século XIX, compreendia um método de ginástica pautado na ciência, com fins pedagógicos e sociais. De acordo com Soares (2001, p. 57), esse método foi pensado para banir os vícios da sociedade, 
entre os quais o alcoolismo, pois a ciência o colocava como um "instrumento capaz de criar indivíduos fortes, saudáveis e livres de vícios, preocupados com a saúde física e moral". Conforme Teixeira (2004), do ponto de vista pedagógico, Fernando de Azevedo acreditava que nenhuma escola ou método superava o sueco e, ao fazer a opção por este, não desconsiderava a existência e o valor de outros métodos, mas sim questionava suas adequações ao ambiente escolar. Vale mencionar que na relação do material didático previsto para as escolas primárias do Estado, até o ano de 1929, apenas a obra de Fernando de Azevedo - Da Educação Physica — fora selecionada para leitura na disciplina de Gymnastica (Aranha, 1929, p. 33).

Nesse processo de (in)definições no ambiente escolar sul-rio-grandense, nas primeiras décadas do século XX, a Gymnastica aparece como a primeira forma de sistematização das práticas corporais nos currículos dos cursos de formação docente. Se analisarmos a grade curricular com relação à carga horária semanal das disciplinas do Curso Complementar, exposta na nova reforma por meio do decreto-lei n. 2.224, de 29 de novembro de 1916 (Lyra, 2013), podemos perceber que a disciplina de Gymnastica finalmente se consolidou no arranjo mais geral do currículo, deixando de fazer parte, efetivamente, dos saberes da disciplina de Pedagogia.

No entanto, as lições práticas voltadas à educação physica, no sentido amplo, permaneceram espalhadas no currículo de formação e, de forma pontual, eram encontradas na disciplina Liç̧óes praticas de Pedagogia. Por sua vez, a criação da disciplina de Gymnastica representou a delimitação espaçotemporal dos conteúdos no arranjo mais geral do referido currículo, fazendo com que uma leitura diferenciada de suas funções pedagógicas começasse a ser feita. Ainda que tivéssemos nas escolas uma situação bastante limitada no que se refere à prática efetiva da aula de Gymnastica, sua especificação no currículo de formação docente demonstra uma nova importância que começava a ser dada a seus saberes não somente na vida escolar, mas também na vida da sociedade em que essa escola estava inserida.

Outra mudança pode ser encontrada na não especificação das práticas ligadas à ginástica sueca, como assim trazia o currículo de 1909. Talvez fosse necessário um estudo mais aprofundado para que pudéssemos pontuar com precisão a real aplicação e o alcance da Gymnastica Sueca nas escolas do Rio Grande do Sul desse momento. Nossa cautela nos leva a afirmar apenas a sua condição de prática curricular não hegemônica, que dividia espaços com outras formas de se fazer gymnastica e, por vezes, com a ausência total de quaisquer sistematizações de fato.

Um dos exemplos dessa coexistência de modelos de gymnasticas nas escolas do estado pode ser encontrado na reportagem jornalística trazida abaixo. Fazendo parte da coluna Ponto de Vista do então circulante jornal Diário de Notícias, um leitor que preferiu não se identificar (fazendo uso, para isso, apenas das iniciais E.M.) enviou ao referido jornal suas percepções sobre uma aula de Gymnastica que presenciou na época, em uma das escolas de Porto Alegre. Em sua descrição, é possível identificarmos certa propriedade de causa nos termos elencados e nos argumentos que defende ou rechaça, o que nos leva a pensar em suas relações diretas com a área em questão. Para além, suas palavras apontam similaridades da prática retratada com os preceitos da Gymnastica Francesa, segundo a qual se previa a utilização precípua dos exercícios militares: 
[...] quem quer que transite á manhã dos dias uteis pelas imediações do alteroso edifício do Collegio Estadual Fernando Gomes, á rua Duque de Caxias, verá, quasi que quotidianamente, nas ruas adjacentes, uns 150 meninos, de 6 (si tanto) até o máximo de 12 annos de idade, com carabinas confeccionadas de madeira, ás costas, formados em batalhões, sob o comando de um sargento do Exercito, executando evoluções estrictamente militares. Com um desvio funcional, que ninguém lhe nega, mas bem digno de mais nobre finalidade, o referido instructor incute nos pequeninos o manejo da arma, exercita o desenvolvimento por esquadras, a formação dos pelotões de combate e demais evoluções concernentes á arte da guerra, militarista, em summa, o espirito receptivo e moço dos innocentes. A quem quer que observe, irrita essa orientação, attentatoria, aliás, das próprias adiantadas disposições do Regulamento da Instruç̧ão Publica, [refere-se ao Decreto n. 3.898 de 14 de outubro de 1927, art. 28 §] que prescreve os exercícios physicos e nunca instrucçôes technico-militar. [...] Recriminemos o fomento desses enthusiasmos bellicos na terra boa da America Latina! Aperfeiçoemos a mocidade physica, cívica e moralmente para a gloria da Patria. (Um Apello, 1928, [n.p.])

Nesse cenário, o ano de 1927 foi marcado, como aponta a reportagem acima, pela expedição de um novo Regimento Interno para os estabelecimentos de ensino público do estado. Ainda que em tal documento não tenha sido apresentada a elaboração concreta de um novo quadro curricular a ser cumprido para a formação do professorado, faz-se interessante o destaque de alguns aspectos que se relacionavam aos contornos previstos para a Gymnastica no processo formativo. Percebe-se, sobretudo, a sua ligação direta com a perspectiva de modernização da sociedade sul-rio-grandense, via modernização das práticas educacionais.

\section{CONSIDERAÇÕES FINAIS}

Neste estudo, buscamos evidenciar os contornos que a educação física recebeu durante seu processo de estabelecimento como parte integrante dos currículos de formação de professores primários do estado do Rio Grande do Sul. A partir da interpretação da documentação, foi possível evidenciarmos que apesar de, inicialmente, haver a ideia de concentrar os conhecimentos referentes ao movimento humano no interior de disciplinas pontuais, tais como na Gymnastica, ou mesmo de espalhá-los por todas as dimensões escolares por intermédio da educação physica, vimos que ocorreu a consolidação desse saber disciplinar nos currículos dos cursos de formação docente do estado, embora de forma lenta em relação às demais disciplinas.

Nas fontes consultadas, evidenciou-se que, no currículo da Escola Normal vigente no ano de 1872, os conhecimentos relativos à Gymnastica estavam ausentes. Essa conformação alterou-se a partir da reformulação curricular de 1877, quando tais saberes passaram a compor a disciplina denominada Gymnastica, Esgrima e Exercícios Militares. Após um novo período de ausência dos referidos saberes no currículo da Escola Normal, observamos que a criação dos colégios distritais, 
no ano de 1901, tornou o curso de formação mais amplo, alargando-o para três anos de duração. Nessa (nova)conformação, a disciplina de Gymnastica, embora presente nos três anos de curso, esteve elencada em último lugar na ordem dos saberes. Além disso, os tempos destinados ao seu aprendizado também eram restritos e, dentre as 28 horas que compunham a semana escolar, apenas 1 hora destinava-se à Gymnastica.

Diante disso, observamos que a admissão da educação física enquanto disciplina curricular nos cursos de formação docente não se deu de forma linear. As fontes consultadas revelaram que no ano de 1906 a educação física torna-se, também, parte da disciplina denominada "Pedagogia - sua historia, educação physica, intellectual e moral, methodologia, practica do ensino". De outra forma, podemos pensar que a própria disciplina de Pedagogia ampliou-se e passou a dedicar-se também às questões voltadas ao corpo. Nesse sentido, nossa compreensão nos levou a supor que o curso de formação docente agia no sentido de preparar o professor para o trabalho com a educação física, e não formar um professor específico para a referida disciplina.

A educação física, por meio da disciplina de Gymnastica, se consolidou no arranjo curricular de formação docente após a reforma expressa pelo decreto-lei n. 2.224, de 1916 (Rio Grande do Sul, 1916). A partir de então, a disciplina teve seu espaçotemporal delimitado, o que fez com que a leitura de suas funções pedagógicas começasse a ser feita. Essa atmosfera revelou que a presença da educação física ampliou-se no arranjo curricular na medida em que foi considerada como um elemento de transformação nos debates educacionais modernos. Coube à educação física, portanto, um movimento de entrada sutil e lento no ambiente educacional. Ademais, foi possível identificarmos a presença de não apenas uma forma de ensinar educação física, mas sim de concepções variadas, provenientes de diferentes correntes de pensamento, que refletiam, justamente, a falta de um trabalho unificado e centralizado desde a preparação dos professores.

\section{REFERÊNCIAS}

Aranha, O. Relatório apresentado ao Presidente do Estado do Rio Grande do Sul Getúlio Vargas. Porto Alegre: A Federação, 28 ago. 1929.

Azevedo, F. Da educação física: o que ela é, o que tem sido e o que deveria ser (seguido de Antinoüs). São Paulo: Melhoramentos, 1960.

. História de minha vida. Rio de Janeiro: José Olympio, 1971.

BAR bosa, R. Reforma do ensino primário e várias instituiçôes complementares da instrução pública: 1883. Rio de Janeiro: Ministério da Educação e Saúde, v. 10, t. 1.1946.

Camargo, E. A. S. P. A Poesia do corpo: a defesa de uma moral austera. Educação e Sociedade, Campinas, v. 27, n. 94, p. 13-46, jan./abr. 2006. Disponível em: <http://www. cedes.unicamp.br>. Acesso em: 21 out. 2008.

Castilhos,J. P. Mensagem enviada à Assemblea dos Representantes do Estado do Rio Grande do Sul. Porto Alegre: Typografia de Cesar Reinhardt, 1895. Documento do Instituto Histórico e Geográfico do Rio Grande do Sul. 
. Mensagem que acompanhou a proposta do orçamento para o exercício de 1897 apresentada à Assemblea dos Representantes do Estado do Rio Grande do Sul. Porto Alegre: Typografia de Cesar Reinhardt, 1896. Documento do Instituto Histórico e Geográfico do Rio Grande do Sul.

Corsetti, B. Análise documental no contexto da metodologia qualitativa: uma abordagem a partir da experiência de pesquisa do Programa de Pós-Graduação em Educação da Unisinos. UNIrevista, São Leopoldo, v. 1, n. 1, p. 32-46, jan. 2006.

. Cultura política positivista e educação no Rio Grande do Sul/Brasil (1889/1930). Cadernos de Educação, Pelotas, v. 31, n. 55, p. 69, jul./dez. 2008.

Julia, D. A cultura escolar como objeto histórico. Revista Brasileira de História da Educação, Campinas, n. 1, p. 9-44. 2001.

Lima, H. I. Fernando de Azevedo e o Projeto Liberal de Educação. Revista de Pedagogia, Brasília, v. 3, n. 5, jan./jul. 2002. Número Especial sobre Fernando de Azevedo. Disponível em: <http://www.fe.unb.br/revistadepedagogia>. Acesso em: 21 out. 2008. Lyra, V. B. A Criação da Escola Superior de Educação Física do Rio Grande do Sul: Formação de professoras(es) para a construção do campo (1940-1970). 2013. 265 f. Tese (Doutorado em Ciências do Movimento Humano) - Universidade Federal do Rio Grande do Sul, Porto Alegre, 2013.

Marinho, I. P. Contribuição para a bistória da educação física: Brasil Colônia - Brasil Império - Brasil República. Rio de Janeiro: Imprensa Nacional, 1943.

. História da educação física e desportos no Brasil. Rio de Janeiro: DEF-MÊS, 1952.

Neves, A. L. O professor Fernando de Azevedo. Revista de Pedagogia, Brasília, v. 3, n. 5,jan./jul.2002. Número Especial sobre Fernando de Azevedo. Disponível em: <http:// www.fe.unb.br/revistadepedagogia>. Acesso em: 15 out. 2009.

PAIVA, F. S. L. Sobre o pensamento médico-higienista oitocentista e a escolarização: condições de possibilidades para o engendramento do campo da Educação Física no Brasil. 2003. Tese (Doutorado em Educação) - Universidade Federal de Minas Gerais, Belo Horizonte, 2003.

. Notas para pensar a Educação Física a partir do conceito de campo. Perspectiva, Florianópolis, v. 22, p. 51-81, jul./dez. 2004.

Piccoli, J. C. J. Educação Física na escola pública do Rio Grande do Sul: antecedentes históricos (1857-1984). Pelotas: Editora da UFPEL, 1994.

Pimentel, A. O método da análise documental: seu uso numa pesquisa historiográfica. Cadernos de Pesquisa, São Paulo, n. 114, p.179-195, nov. 2001.

Pykosz, L. C.; Taborda DE Oliveira, M. A. A higiene como tempo e lugar da educação do corpo: preceitos higiênicos no currículo dos grupos escolares do Estado do Paraná. Currículo sem Fronteiras, Rio de Janeiro, v. 9, p. 135-158, 2009.

Rio Grande Do Sul. Acto Provincial de 19 de fevereiro de 1872. Aprova os regulamentos do Atheneu Rio-Grandense e da Escola Normal de Porto Alegre. Sancionada pelo então presidente da província de São Pedro do RS, Jeronimo Martiniano Figueira de Mello. 
Lei Provincial n. 32 de 7 de março de 1877. Aprova o Regulamento da Escola Normal de Porto Alegre. Colecção de Atos, Regulamentos e Instrucções expedidos pela Presidência da Provincia em 1877. Porto Alegre: Typographia do Mercantil, 1881. Instrucção Publica. Documento do Arquivo Histórico do Rio Grande do Sul.

. Lei Provincial n. 1340 de 2 de maio de 1881. Aprova o Regulamento para Reorganização da Escola Normal de Porto Alegre. Sancionada pelo então presidente da província de São Pedro do RS, Fransisco de Carvalho Soares Brandão. In: COLECÇÃO de Leis e Resoluções. Porto Alegre: [s.n.],1881. Documento do Arquivo Histórico do Rio Grande do Sul.

. Decreto n. 89, de 02 de fevereiro de 1897. Dispões sobre a reformulação do ensino público primário e secundário no estado do Rio Grade do Sul: Legislação, Leis, Actos e Decretos do Governo do Estado do Rio Grande do Sul, 1897. Documento do Arquivo Histórico do Rio Grande do Sul. Porto Alegre.

. Decreto n. 373 de 14 de março de 1901. Institui na capital do Estado um Colegio Distrital. Porto Alegre: Officina Typographica do Jornal do Commercio, 1901a. Documento do Arquivo Histórico do Rio Grande do Sul.

. Decreto n. 385 de 9 de maio de 1901. Aprova o Regimento interno dos Colegios Distritais. Legislação. Porto Alegre: Officina Typographica do Jornal do Commercio, 1901b. Documento do Arquivo Histórico do Rio Grande do Sul.

. Decreto n. 397 de 27 de agosto de 1901. Institue dois colégios districtais, um em Santa Maria e outro na Cruz Alta. Porto Alegre: Officina Typographica do Jornal do Commercio, 1901c. Documento do Arquivo Histórico do Rio Grande do Sul.

. Decreto n. 468 de 2 de fevereiro de 1902. Institue collegios districtais em Santa Cruz, Taquary e S. João do Montenegro. Porto Alegre: Officina Typographica do Jornal do Commercio, 1902. Documento do Arquivo Histórico do Rio Grande do Sul.

. Decreto n. 874 de 28 de fevereiro de 1906. Reorganiza o serviço de instrucção publica do Estado. Porto Alegre: Officina Typographica do Jornal do Commercio, 1906. Documento do Arquivo Histórico do Rio Grande do Sul.

. Decreto n. 1479 de 26 de maio de 1909. Modifica o programma do ensino complementar e CREA collegios elementares no estado. Leis, decretos e actos do Governo do Estado do Rio Grande do Sul, 1909. Porto Alegre: Officina da Livraria de Carlos Echenique, 1910.

. Decreto-Lei n. 2224 de 29 de novembro de 1916. Provê sobre o ensino elementar e complementar ministrado no Estado. Porto Alegre: Officina Typographica do Jornal do Commercio, 1916. Documento do Arquivo Histórico do Rio Grande do Sul.

SoAres, C.L.Educaşão fisisica: raízes europeias e Brasil. Campinas: Autores Associados, 1994.

. Corpo, Conhecimento e Educação: notas esparsas. In: (Org.). Corpo

e História. Campinas: Autores Associados, 2001. p. 109-129.

Teixeira, A. H. L. A gymnastica do gymnasio mineiro: 1890-1916. 2004. Dissertação (Mestrado em Educação) - Universidade Federal de Minas Gerais, Belo Horizonte, 2004. Tesche, L. A afirmação de uma identidade. Visão Global, v. 11, n. 2, p. 239-254, jul./dez. 2008. 
Um Apello. Jornal Diário de Notícias, Porto Alegre, 1928.

VAGo, T. M. Cultura Escolar, cultivo de corpos: educação physica e gymnastica como práticas constitutivas dos corpos de crianças no ensino público primário de Belo Horizonte (1906-1920). Bragança Paulista: Edusf, 2002.

VIDAL, D. G.; Faria Filho, L. Culturas escolares: estudo sobre práticas de leitura e escrita na escola pública primária: Brasil e França, final do século XIX. Campinas: Autores Associados, 2005.

VIÑao, A. Historia de La educación e historia cultural: posibilidades, problemas, cuestiones. Revista Brasileira de Educação, Rio de Janeiro, n. 0, p. 63-82, set./dez. 1995. WerLe, F. O. C. O nacional e o local: ingerência e permeabilidade na educação brasileira. Bragança Paulista: EDUSF, 2005.

\section{SOBRE AS AUTORAS}

Vanessa Bellani Lyra é doutora em ciências do movimento humano pela Universidade Federal do Rio Grande do Sul (UFRGS). Professora da Universidade de Caxias do Sul (UCS).

E-mail:vblyra@ucs.br

Janice Zarpellon Mazo é doutora em ciências do desporto pela Universidade do Porto (Portugal). Professora da Universidade Federal do Rio Grande do Sul (UFRGS).

E-mail: janice.mazo@ufrgs.br

Tuany Defaveri Begossi é doutoranda em ciências do movimento humano pela Universidade Federal do Rio Grande do Sul (UFRGS).

E-mail: tuany_begossi@hotmail.com

Recebido em 9 de novembro de 2016

Aprovado em 27 de março de 2017 